\title{
UPPER CRUSTAL STRUCTURE IN SOUTH KYUSHU
}

\author{
Toshiki KaKUTA \\ Institute of Earth Sciences, Faculty of Science, \\ Kagoshima University, Kagoshima, Japan \\ (Received October 22, 1981; Revised March 2, 1982)
}

\begin{abstract}
Explosion seismic data in South Kyushu are reexamined and a model of the upper crustal structure is presented. A layer of P-wave velocity $V_{P}=$ $4.9 \mathrm{~km} / \mathrm{sec}$ is widely distributed over the profile. Below the layer, lateral variations in P-wave velocity are observed: $V_{P}=6.1 \mathrm{~km} / \mathrm{sec}$ in the western part of the profile, $V_{P}=5.9 \mathrm{~km} / \mathrm{sec}$ in the eastern part and $V_{P}=5.7 \mathrm{~km} / \mathrm{sec}$ in the central part. A depression of this layer is confirmed in the central part, or in the low velocity region. The depth of this layer increases abruptly by $1-2 \mathrm{~km}$ at the west boundary of the region and decreases gradually toward the east. This layer subsides again by about $2 \mathrm{~km}$ to the west of Miyakonojo City in the Osumi Peninsula. This is suggested by geological evidence as well. These variations in the depth of the layer can be interpreted well using gravity data.

Decreases in wave velocity are ascertainable in the region under the Sakurajima Volcano and the Aira Caldera where seismic waves are highly attenuated.
\end{abstract}

\section{Introduction}

Seismological investigations by artificial explosions, blasted in South Kyushu from 1972 to 1977, have already been reported by ONo et al. $(1977,1978)$. They presented a model of the crustal structure along an E-W profile across South Kyushu by analyzing seismic refraction data for two shots: the Sendai Explosion (SP. I) and the Nichinan Explosion (SP. II) of 1973 [in Paper I (ONO et al., 1977)]. In an N-S profile along the Osumi Peninsula, the above researchers indicated that the depth of the Mohorovičic discontinuity is much greater than the former estimation by gravity data or by phase velocity data of Rayleigh waves [in Paper II (ONO et al., 1978)]. They also revealed by fan shooting observations the existence of an anomalous region where seismic waves are highly attenuated.

In the present report, the explosion seismic data in South Kyushu are reexamined, with the exception of those of the Tanegashima Explosion (SP. VII). Reexaminations are required for the following reasons; 1) In the previous papers, seismic refraction data were not analyzed for four explosions, SP. I, SP. III, SP. IV and SP.V of 1974. As these explosions were observed at sites denser than for the two explosions of 1973, the detailed structure of the upper mantle can be investigated. 2) P-wave velocity of their third layer is $5.6 \mathrm{~km} / \mathrm{sec}$ in the E-W profile across the Osumi Peninsula while $5.9 \mathrm{~km} / \mathrm{sec}$ in the $\mathrm{N}-\mathrm{S}$ profile. This difference will require careful examination. 3) A low P-wave velocity was 
supposed under the Sakurajima Volcano. It has, however, not been found whether such a decrease in wave velocity occurs all over the highly attenuative region.

We also investigate the gravity data surveyed by Yokoyama and Okawa [see TsuBor $(1979$, p. 254)]. The gravity data provide us with useful information on the appropriateness of the crustal structure model.

\section{Travel Time Curves and Estimated Wave Velocities}

Shot points and observation sites are shown in Fig. 1. The S-sites, $\mathrm{S}_{1}-\mathrm{S}_{15}$, and the T-sites, $T_{1}-T_{11}$, are for refraction observations; the S-sites are for SP. I and SP. II of 1973, and the T-sites are for SP. I, SP. III, SP. IV and SP. V of 1974. To avoid confusion in the figure, several site-signs are omitted. The S-sites, with the exception of two, differ from the T-sites; $S_{7}$ is the same as $T_{8}$ and $S_{9}$ as $T_{11}$. The western part of the T-profile is shifted to the south of the S-profile by several kilometers.

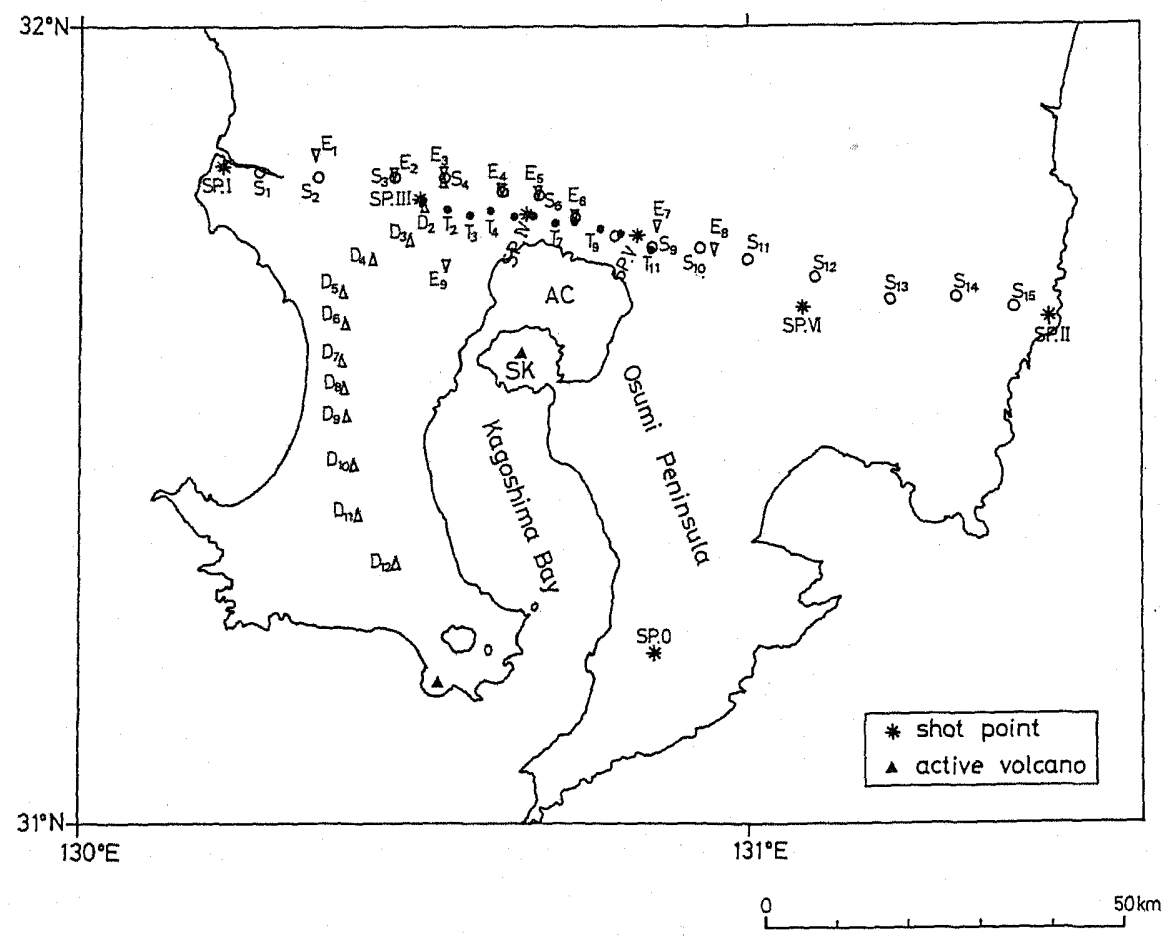

Fig. 1. Shot points and observation sites. The shot points are seven: SP. 0-VI. The S- and T-sites are for refraction observations; the S-sites are for SP. I and SP. II of 1973, and the T-sites are for SP. I, SP. III, SP. IV and SP. V of 1974. The E- and D-sites are for fan shooting observations of SP. 0 of 1972 and SP. VI of 1975, respectively. On the D-sites, refraction observations were also carried out for SP. III in 1975. AC, Aira Caldera; SK, Sakurajima Volcano. 
The E- and D-sites are for fan shooting observations of the Onejime Explosion (SP. 0) of 1972 and the Sueyoshi Explosion (SP. VI) of 1975. They are distributed on a semi-circle around the Sakurajima Volcano and the Aira Caldera. In these sites, $E_{3}$ and $D_{1}$ are the same as $S_{4}$. Seismic refraction observations were also carried out on the D-profile for SP. III in 1975. Details concerning shot data are listed in Paper II.

With reference to seismic record sections, first arrivals are all reexamined on seismograms, and later phases, if appreciable, are picked up as well.

Travel times on the S- and T-profiles are plotted in Figs. 2 and 3 with different marks according to their accuracies, where they are ranked in four categories: A $(|\Delta t| \leq 10 \mathrm{msec}), \mathrm{B}(10 \mathrm{msec}<|\Delta t| \leq 30 \mathrm{msec}), \mathrm{C}(30 \mathrm{msec}<|\Delta t| \leq 50 \mathrm{msec})$ and $\mathrm{D}(50 \mathrm{msec}<|\Delta t| \leq 100 \mathrm{msec})$. Closed marks show $T^{\prime}$ or $T^{\prime \prime}$ travel times, which are calculated by the method of differences (HAGIWARA, 1938; TAZIME, 1977, p. 69-70). A brief description of the $T^{\prime}$ or $T^{\prime \prime}$ travel time is given in Appendix 1. Seismic record sections are also seen in Appendix 2 (Figs. 13 and 14).

From the reduced $T^{\prime}$ travel time curve on the S-profile (Fig. 4), lateral variations of P-wave velocity are inferred: $V_{\mathrm{P}}=6.1 \pm 0.04 \mathrm{~km} / \mathrm{sec}$ in the western part, $V_{P}=5.9 \pm 0.01 \mathrm{~km} / \mathrm{sec}$ in the eastern part and $V_{P}=5.7 \pm 0.10 \mathrm{~km} / \mathrm{sec}$ in the central part. In these computations, later phases are used at $S_{12}$ and $S_{13}$ for SP.II.

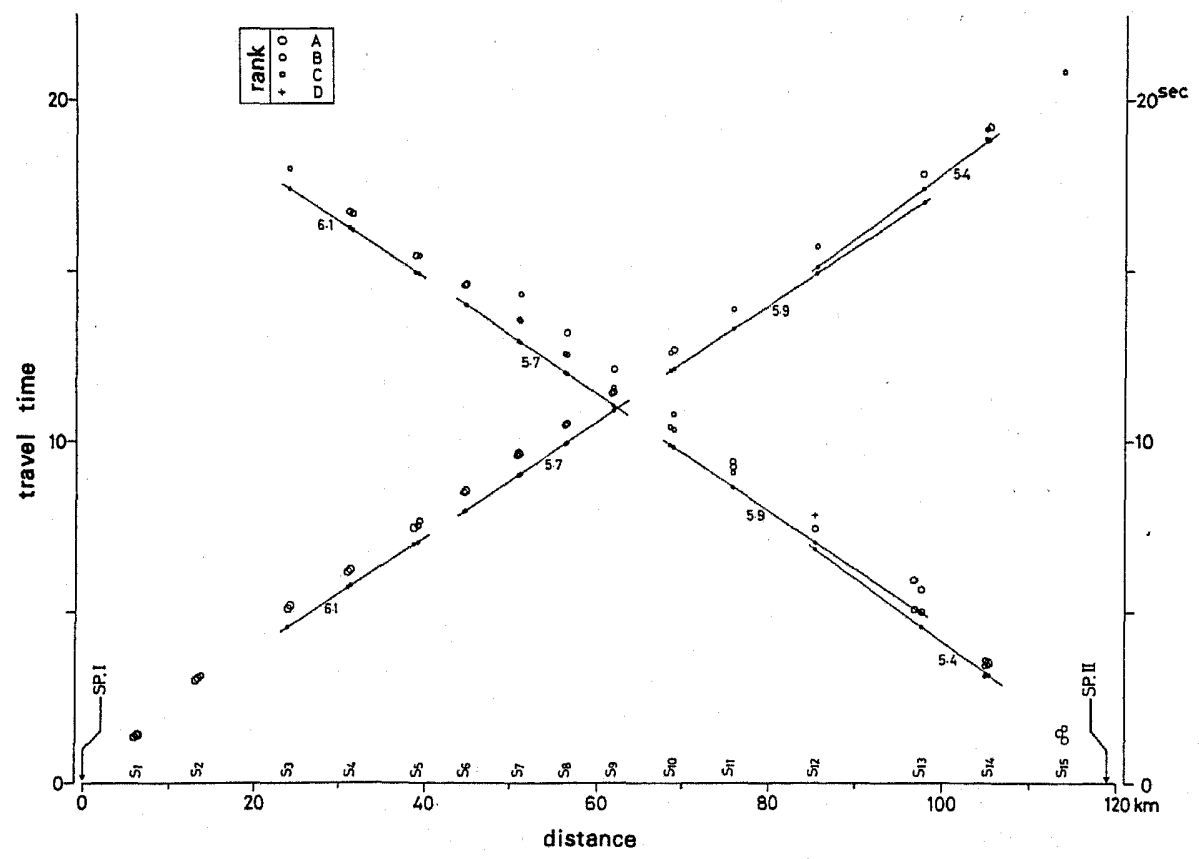

Fig. 2. Travel time curves on the S-profile. Travel times are plotted with different marks according to their accuracies. A small closed circle indicates $T^{\prime}$ or $T^{\prime \prime}$ travel time. Numerals refer to velocities. 
These phases are found on an extension from the first arrival at $S_{10}$ through that at $S_{11}$ on the seismic record section for SP. II (Fig. 13(b)). The P-wave velocity estimated by accepting them gives far smaller residuals in $T^{\prime}$ travel time at $\mathrm{S}_{10}$ and $S_{11}$ than the velocity in Paper $I$.

The $T^{\prime}$-curve such as shown in Fig. 4 is the typical one when a low velocity region exists between high velocity regions with an overlying low velocity layer (TAZIME, 1963; OKADA et al., 1970). The $T^{\prime}$-curve derived from the observations of SP. I and SP. V of 1974 also gives $V_{P}=6.1 \pm 0.04 \mathrm{~km} / \mathrm{sec}$ between $T_{1}$ and $T_{4}$ (Fig. 3).

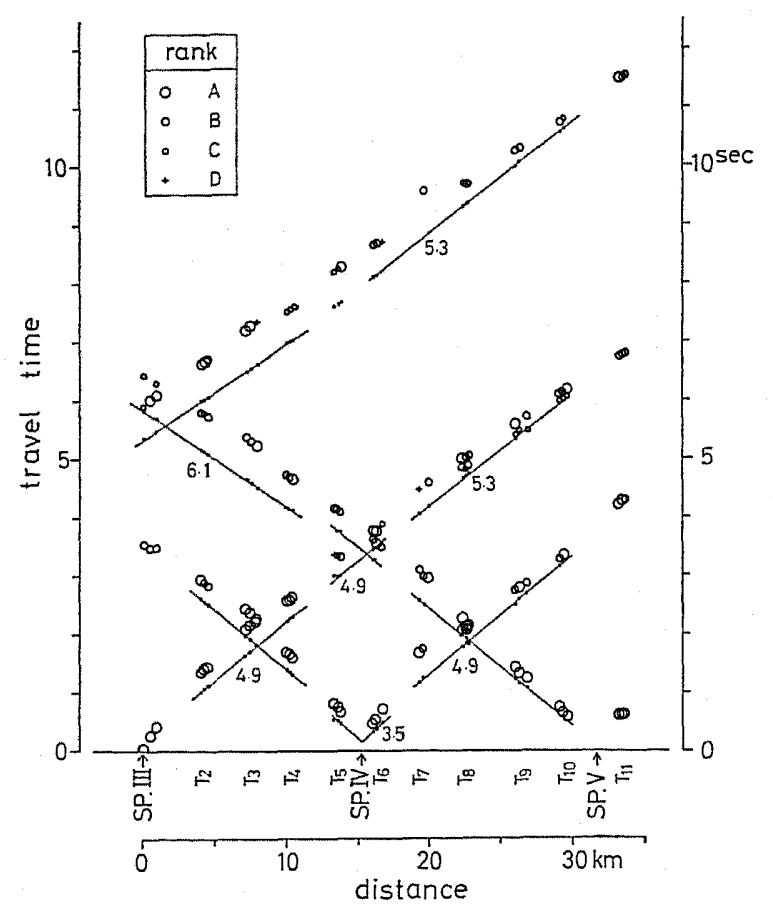

Fig. 3. Travel time curves on the T-profile. The legends are the same as those in Fig. 2.

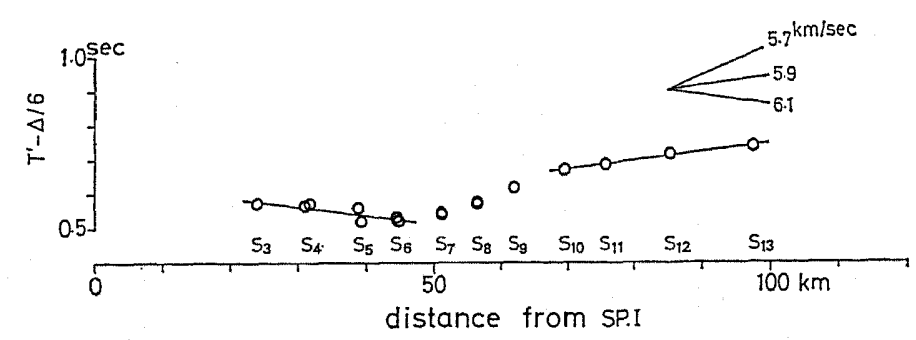

Fig. 4. Reduced $T^{\prime}$ travel time curve on the S-profile. This is a typical one when a low velocity region exists between high velocity regions with an overlying low velocity layer. 
It is inferred from $T^{\prime}$-curves on the T-profile that the layer of $V_{\mathrm{P}}=4.9 \mathrm{~km} / \mathrm{sec}$ overlies the above-mentioned layer (Fig. 3). By using the equation (A.7) in Appendix, $V_{P}=4.9 \mathrm{~km} / \mathrm{sec}$ is also derived from the $T^{\prime \prime}$-curve for the observations at the sites $S_{12}$ to $S_{14}$ if the velocity of the underlying layer is assumed as $5.9 \mathrm{~km} / \mathrm{sec}$ (Fig. 2). An apparent gradient of the travel time curve gives $V_{\mathrm{P}}=4.9 \mathrm{~km} / \mathrm{sec}$ between $S_{1}$ and $S_{3}$ (Paper I). These imply that the layer of $V_{P}=4.9 \mathrm{~km} / \mathrm{sec}$ is widely distributed over the $T$ - or S-profile.

If $V_{\mathrm{P}}=4.9 \mathrm{~km} / \mathrm{sec}$ is the velocity of the overlying layer, $V_{\mathrm{P}}=5.7 \mathrm{~km} / \mathrm{sec}$ is derived in the central part of the profile from $T^{\prime \prime}$-curves between $T_{7}$ and $T_{10}$ (Fig. 3).

P wave velocities of layers overlying the layer of $V_{\mathrm{P}}=4.9 \mathrm{~km} / \mathrm{sec}$ are estimated from the observations at the sites nearest to shot points; $V_{\mathrm{P}}=2.7 \mathrm{~km} / \mathrm{sec}$ is estimated from the $T^{\prime \prime}$-curve at $\mathrm{T}_{6}$ by using travel times for SP. IV and SP. V of 1974 (Fig. 3). This value is consistent with those derived from the first arrivals at $\mathrm{T}_{1}$ for SP. III or at $\mathrm{T}_{5}$ for SP. IV. On the other hand, the first arrivals at $\mathrm{T}_{10}$ or $\mathrm{T}_{11}$ for SP. $\mathrm{V}$ give $V_{\mathrm{P}}=3.5-3.9 \mathrm{~km} / \mathrm{sec}$ under the assumption of direct waves. The $T^{\prime \prime}$-curve between $S_{13}$ and $S_{15}$ also gives $V_{\mathrm{P}}=3.9 \mathrm{~km} / \mathrm{sec}$.

The layer of $V_{\mathrm{P}}=2.7 \mathrm{~km} / \mathrm{sec}$ is apparently not superficial on the west of $T_{6}$ (Fig. 3). Hence, we assume a superficial layer of $V_{\mathrm{P}}=1.0 \mathrm{~km} / \mathrm{sec}$, which was observed by Омоте et al. (1975) as the velocity in a deeper part of "Shirasu", or pyroclastic flow deposits.

Thus the upper crustal structure is composed of five layers: the superficial layer of $V_{P}=1.0 \mathrm{~km} / \mathrm{sec}$, the second of $V_{P}=2.7 \mathrm{~km} / \mathrm{sec}$, the third of $V_{P}=3.9 \mathrm{~km} /$ $\mathrm{sec}$, the fourth of $V_{\mathrm{P}}=4.9 \mathrm{~km} / \mathrm{sec}$ and the fifth of $V_{\mathrm{P}}=5.7-6.1 \mathrm{~km} / \mathrm{sec}$. On the eastern part of the S-profile, the first layer is neglected because neither $V_{P}=1.0$ $\mathrm{km} / \mathrm{sec}$ nor $V_{\mathrm{P}}=2.7 \mathrm{~km} / \mathrm{sec}$ was observed.

\section{Estimations of Delay Times}

Delay times of the fourth layer can be accurately estimated on the T-profile because there are observation sites on both sides of SP. IV or SP. V, and because refracted waves from the layer were successfully observed at all sites. On the Sprofile, refracted waves from the layer were only observed one-way and appeared at most sites as a later phase. For SP. II, they appeared as the first arrival between $S_{12}$ and $S_{14}$ while as a later phase between $S_{7}$ and $S_{11}$ and at $S_{15}$ (Figs. 2 and 13). Delay times at some $S$-sites are estimated even from one-way observations since the delay times at $S_{7}$ and $S_{9}$ are known as those at $T_{8}$ and $T_{11}$, respectively. On the other hand, for SP. I, refracted waves from the layer are hardly traced in later phases at sites more distant than $\mathrm{S}_{4}$ (Fig. 13). Hence, we assume that delay times of the fourth layer vary almost linearly with distance between $S_{3}$ and the shot point SP. I. The delay time at $S_{4}$ is estimated from the first arrival for SP. III of 1975.

Because of lateral variations in wave velocity, computations of delay times 
of the fifth layer are rather complicated: at a site near the boundary between two regions with different velocities, the waves from two different shots in the opposite directions are refracted from different regions. The delay time at such a site cannot be estimated without knowledge of the locations of boundaries.

First arrivals between $T_{1}$ and $T_{4}$ are presumably refracted waves from the region of $V_{\mathrm{P}}=6.1 \mathrm{~km} / \mathrm{sec}$ for both SP. I and SP. V (Fig. 3). The travel time between shot points of SP. I and SP. V, $T_{\mathrm{I}, \mathrm{V}}$, is estimated by interpolating those at $T_{10}$ and $T_{11}$ for SP. I. Then we obtain delay times between $T_{1}$ and $T_{4}$ and at the shot point SP. I. The delay time at the shot point SP. I, $e_{\mathrm{I}}$, is estimated as 0.65 sec.

The travel time between shot points of SP. I and SP. II, $T_{\mathrm{I}, \mathrm{II}}$, and the delay time at the shot point SP. II, $e_{\mathrm{II}}$, are estimated from the following equations:

$$
\begin{aligned}
& T_{\mathrm{I}, \mathrm{II}}=T_{\mathrm{II}}(\Delta)-T_{\mathrm{I}}(\Delta)+2\left(\Delta / V_{\mathrm{P} 5}+e_{\mathrm{I}}\right), \\
& e_{\mathrm{II}}=(1 / 2)\left[T_{\mathrm{I}, \mathrm{II}}-T_{\mathrm{I}}(x)+T_{\mathrm{II}}(x)\right]-x / V_{\mathrm{P} 5},
\end{aligned}
$$

where $x=\Delta_{\mathrm{I}, \mathrm{II}}-\Delta, \Delta_{\mathrm{I}, \mathrm{II}}=$ distance between shot points of SP.I and SP.II, $\Delta=$ distance from SP. I to a site, $V_{\mathrm{P} 5}=$ velocity of the fifth layer, $T_{\mathrm{I}}=$ travel time at a site for SP. I, $T_{\mathrm{II}}=$ travel time at a site for SP. II.

We obtain $T_{\mathrm{I}, \mathrm{II}}=22.00 \mathrm{sec}$ from Eq. (1) by using the observations at $\mathrm{S}_{3}$ or $S_{4}$, where the first arrivals are refracted from the region of $V_{P}=6.1 \mathrm{~km} / \mathrm{sec}$. The delay time $e_{\mathrm{II}}$ is estimated as $1.37 \mathrm{sec}$ from the observations of the first arrivals at $S_{10}$ or $S_{11}$ by using the waves refracted from the region of $V_{P}=5.9 \mathrm{~km} / \mathrm{sec}$.

The width of the low velocity region in the central part of the E-W profile

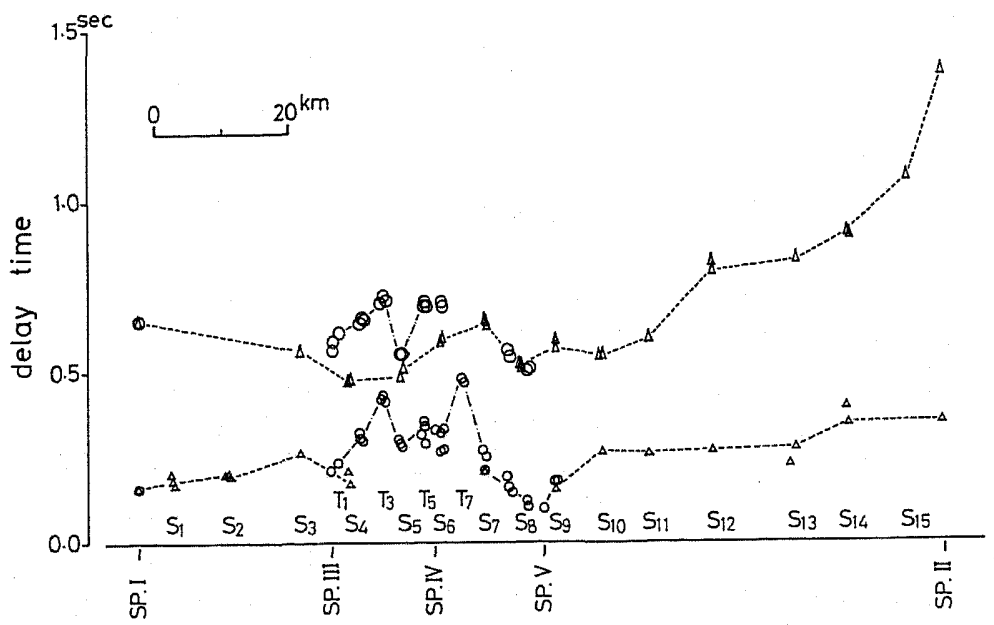

Fig. 5. Delay times of the fourth and fifth layers on the S- and T-profiles. Those of the fourth layer are on the lower and those of the fifth layer are on the upper. Delay times on the S-profile are shown with triangles, and those on the T-profile are with circles. 
across South Kyushu is not sufficiently great for us to estimate the location of the region from travel time data only. Supplemental information for locating the low velocity region is prepared with geological distributions of the Shimanto group, or the sediments of late Mesozoic. While the sediments of early Cretaceous are distributed in the western part of the Osumi Peninsula, they are not found in the central part of South Kyushu, and volcanic rocks of Quaternary are distributed in this region (IMAI et al., 1980). Then we assume that the eastern boundary of the low velocity region corresponds to the boundary between the volcanic rocks of Quaternary and the sediments of Cretaceous. The location of the boundary is assumed at $\Delta=60 \mathrm{~km}$, where $\Delta$ is the distance from SP. I along the S- or T-profile. If $V_{\mathrm{P} 5}=5.7 \mathrm{~km} / \mathrm{sec}$ is accepted in the low velocity region, the western boundary is estimated at $\Delta=46 \mathrm{~km}$. Delay times are then computed at any sites if refracted waves from the underlying region are picked for one shot.

These delay times are shown in Fig. 5. Triangles are the delay times computed for the S-profile and circles for the T-profile; those of the fifth layer are on the upper, and those of the fourth on the lower. They are very complicated between $T_{1}$ and $T_{7}$. The delay time of the fifth layer at the shot point SP. II is abnormally high so that it is hardly explainable with increasing depth of the layer only.

\section{Bouguer Anomalies and Delay Times}

A detailed survey of gravity in South Kyushu has been carried out by Yokoyama and Okawa; their results are seen in Tsuboi's book (TsuBor, 1979, p. 254).

On the S- or T-profile, delay times of the fifth layer are well correlated with Bouguer anomalies which are interpolated on a copy of the original contour map of Yokoyama and Okawa (Fig. 6). The only exception is at the shot point SP. I. Figure 6 illustrates that observed Bouguer anomalies are predominant for a wavelength corresponding to the depth of the fifth layer. A regression

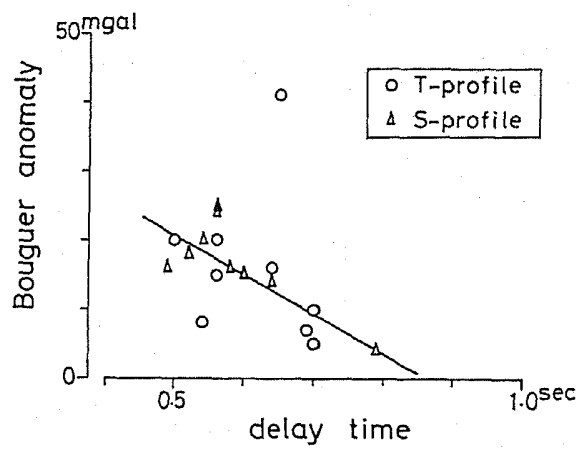

Fig. 6. The relation of Bouguer anomalies with delay times of the fifth layer on the S- and T-profiles. A line indicates a regression equation $\Delta g_{0}{ }^{\prime \prime}=-56.9 e_{\mathrm{S}}+49.0$ (mgal), where $\Delta g_{0}{ }^{\prime \prime}$ is the Bouguer anomaly and $e_{\mathrm{S}}$ is the delay time. 
equation is given for the data on the S- or T-profiles as

$$
\Delta g_{0}{ }^{\prime \prime}=-56.9 e_{\mathrm{s}}+49.0 \quad \text { (mgal) }
$$

where $\Delta g_{0}{ }^{\prime \prime}$ is the Bouguer anomaly and $e_{\mathrm{S}}$ is the delay time of the fifth layer. This equation may give information for the assessments of delay times derived from insufficient data, though it is usable only in a limited range.

A crustal structure model which satisfies delay time data is presented in Fig. 7, where irregularities in layer boundaries are smoothed out. A depression which has been indicated in Paper I is also confirmed in the central part of the profile. It is slightly different from the previous model in its configuration or location of boundaries. An abrupt increase in the depth of the fifth layer occurs between $S_{11}$ and $S_{12}$. Broken lines are the assumed boundaries. By introducing such a boundary, the depth of the fourth or the fifth layer is varied less than several hundred meters only; if the third layer lacks at the shot point SP. III, the depth of the fourth layer may be shallower by one hundred meters or so. Generally speaking, the depth of the fifth layer is almost in accord with the previous model. Differences lie within a kilometer only.

Under the assumption of appropriate densities, theoretical Bouguer anomalies are computed by Talwani's method (TALWANI et al., 1959). They are compared with the observed curve in the upper part of Fig. 7; numerals in parentheses are the assumed densities. This shows an almost satisfactory agreement between theoretical and observational results.

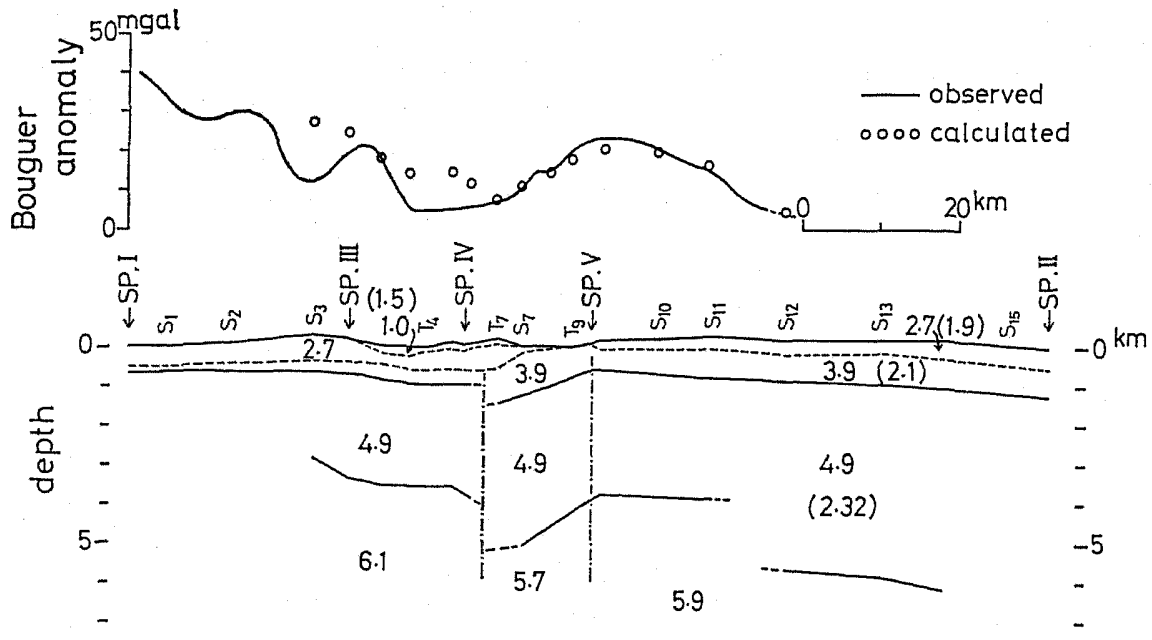

(2.57)

Fig. 7. Underground structure derived on the S- or T-profile. Theoretical Bouguer anomalies are compared with the observed ones on the upper part of the figure. Numerals in parentheses are the assumed densities. The observed Bouguer anomalies are derived by interpolating on the contour map of Yokoyama and Okawa. 


\section{Velocity Anomalies in the Highly Attenuative Region}

It was manifested in Papers I and II that refracted waves from the layer where $\mathrm{P}$-wave velocity is about $6 \mathrm{~km} / \mathrm{sec}$ are highly attenuated under the Sakurajima Volcano and the Aira Caldera. A decrease in wave velocity was also found under the Sakurajima Volcano. It was, however, not recognized whether such a decrease occurs all over the highly attenuative region since travel time anomalies were not observed at any sites except $D_{8}$ and $E_{3}$.

In order to verify whether wave velocity anomalies occur in the highly attenuative region, delay times must be accurately known at sites for fan shooting observations. On the D-profile, if $V_{\mathrm{P}}=6.1 \mathrm{~km} / \mathrm{sec}$ is assumed, refraction observations for SP. III of 1975 provide delay times of the fifth layer between $\mathbf{D}_{4}$ and $D_{12}$; the waves from the refractor appear as the first arrival between $D_{5}$ and $D_{12}$, while as a later phase at $D_{4}$. The delay time at $D_{2}$ is assumed as that at its nearest site, $T_{1}$, which is the nearest site to the shot point SP. III; this is not included in Fig. 1 to avoid confusion. Then at all sites except $D_{3}$, delay times of the fifth layer are estimated. In Fig. 8, Bouguer anomalies and delay times are plotted along the D-profile. Evident inverse correlations are noticed although Eq. (3) does not hold. These correlations suggest that estimations of delay times are reasonable on the D-profile. On the E-profile, several sites are the same as those on the S-profile. Since no refracted waves were picked up at $E_{1}$, it is omitted. The delay time at $E_{7}$ or $E_{8}$ is assumed as that at the respective nearest site. The delay time at $E_{9}$ is estimated from the difference in travel time between $\mathrm{E}_{2}$ and $\mathrm{E}_{9}$ under the assumption of $V_{\mathrm{P}}=6.1 \mathrm{~km} / \mathrm{sec}$. This estimation is consistent with that from Eq. (3).

Reduced travel times are plotted in Figs. 9 and 10, the distance from a fan shooting shot being taken on the abscissa. In Fig. 9, arrivals of rank $\mathrm{E}(|\Delta t|>$ $100 \mathrm{msec}$ ) are added for reference. Travel times corrected with delay time are shown in Figs. 9(a) and 10(a). They are also given in Fig. 11 as a function of azimuth from a shot to the respective site. Irrespective of correction of delay

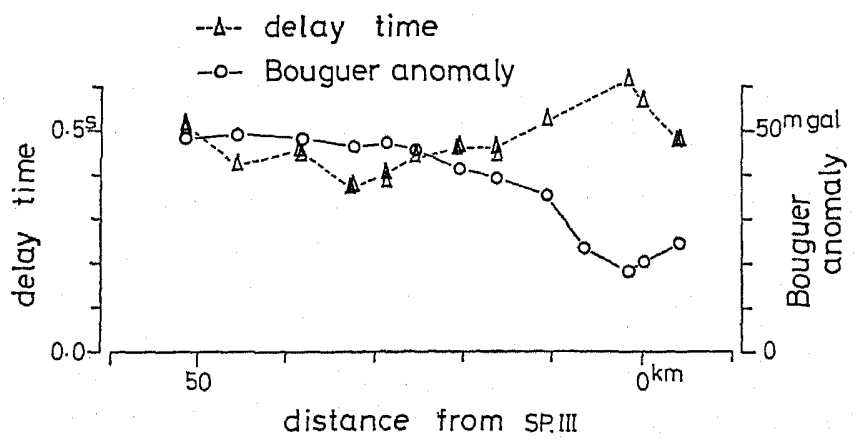

Fig. 8. Bouguer anomalies and delay times of the fifth layer along the D-profile.

The delay times are derived under the assumption of $V_{\mathrm{P}}=6.1 \mathrm{~km} / \mathrm{sec}$. 


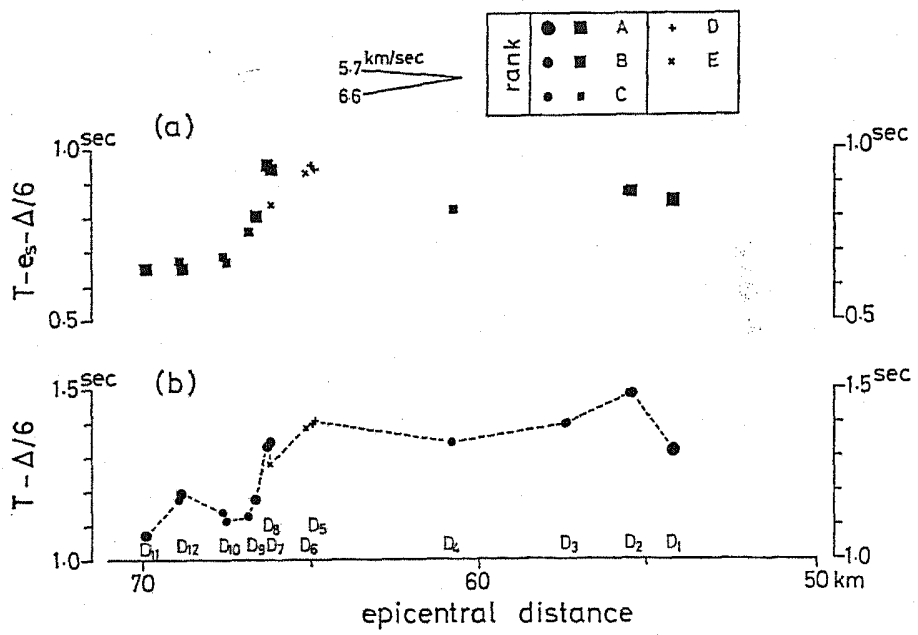

Fig. 9. Reduced travel times on the D-profile. (a) Those corrected with delay time and (b) those uncorrected. Accuracies are shown with different marks.

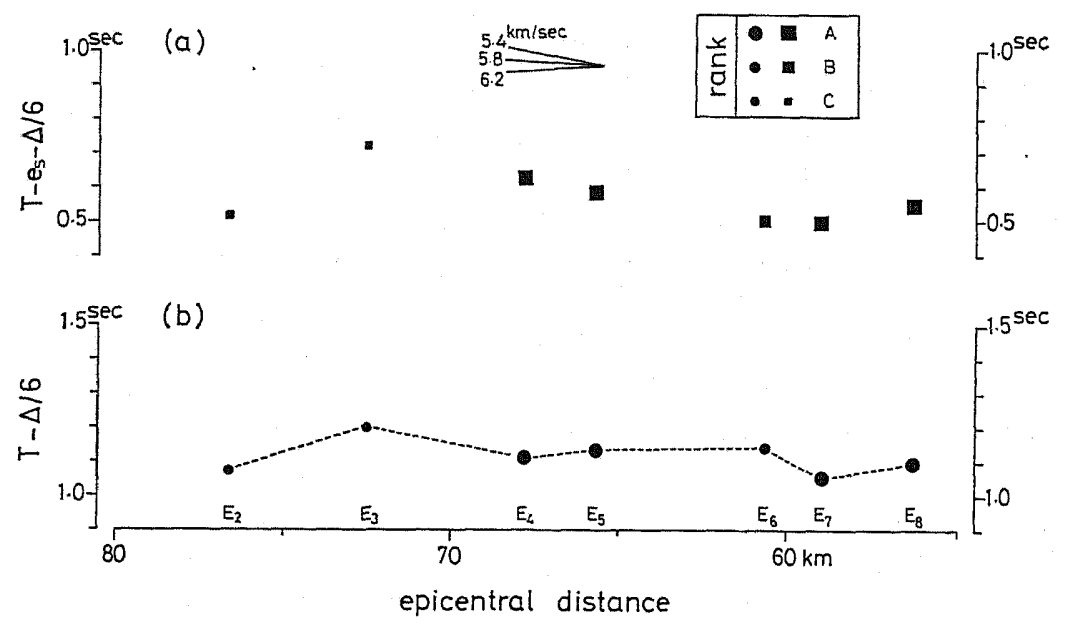

Fig. 10. Reduced travel times on the E-profile. (a) Those corrected with delay time and (b) those uncorrected. Accuracies are shown with different marks.

time, a marked increase in reduced travel time is observed between $D_{1}$ and $D_{8}$. Apparent velocity is about $5.7 \mathrm{~km} / \mathrm{sec}$ between them (Fig. 9(a)). On the Eprofile, travel time anomalies are found only when travel times are corrected with delay time. In Paper II, although arrival times with no correction were almost the same as those in the present report, low values of delay times would be estimated improperly at sites on the east side of the profile because of the assumption of $V_{\mathrm{P}}=5.6 \mathrm{~km} / \mathrm{sec}$ for the refractor. Reduced travel times corrected with delay time increase between $E_{6}$ and $E_{3}$ with increasing distance by the apparent 


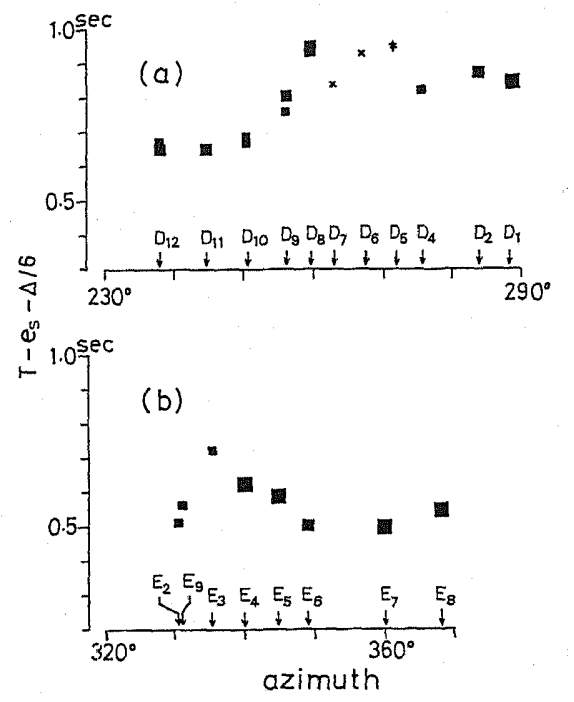

Fig. 11. Reduced travel times corrected with delay time as a function of azimuth from a shot to the respective site. Marks are the same as those shown in Fig. 9 or Fig. 10.

velocity of $5.4 \mathrm{~km} / \mathrm{sec}$ or so (Fig. 10(a)). No anomalies in travel time are observed at $E_{2}$ or $E_{9}$ (Figs. 10(a) and 11(b)). Wave paths to those sites between $D_{4}$ and $D_{8}$ or between $E_{3}$ and $E_{5}$ are in the highly attenuative region (Paper II). The increased delays in reduced travel time at those sites, therefore, indicate that the decrease in wave velocity occurs almost all over the region.

\section{Discussion}

Delay times of the fifth layer between $S_{4}$ and $S_{6}$ are less by $0.2 \mathrm{sec}$ at the maximum than those at the sites between $T_{1}$ and $T_{6}$ with the exception of $T_{4}$ (Fig. 5). This implies that there are irregularities in the depth of the layer by about $500 \mathrm{~m}$; that is, the layer is shallower under those sites between $S_{4}$ and $S_{6}$ or at. $T_{4}$ than their circumferences. In the western part of the S-profile, a complicated geological structure is supposed by HASHImoro et al. (1972). This appears in the gravity data of Yokoyama and Okawa [see TsuBor $(1979$, p. 254)] as well.

An abrupt increase in the depth of the fifth layer occurs between $S_{11}$ and $S_{12}$, or at the west of Miyakonojo City in the Osumi Peninsula (Fig. 7). It is also evident in delay time (Fig. 5). Although there are no indications in delay time whether any breaks occur in the overlying layers between $S_{11}$ and $S_{12}$, the discontinuity corresponds to the geological boundary between the Shimanto group (Cretaceous) and Nichinan group (Paleogene) (IMAI et al., 1980).

Delay times of the fifth layer increase remarkably at $S_{15}$ and the shot point 
SP. II (Fig. 5). In this region, Bouguer anomalies are negative (TsuBor, 1979, p. 266-267). Between $S_{14}$ and $S_{15}$, there is a geological boundary between the Nichinan group (Paleogene) and Miyazaki group (Neogene) (IMAI et al., 1980). Such increases in delay time are possible with an intensive subsidence of the layer to the east or the existence of materials of low wave velocity. The delay time at the shot point SP. II is, however, so high that it is hardly interpretable without materials of low velocity.

Under the assumption of the crustal structure shown in Fig. 7, the delay time at the shot point SP. VI is estimated as $0.69 \mathrm{sec}$ from the travel time of the first arrival at $D_{1}$. This value is reasonable because it is nearly equal to the value estimated from Eq. (3). The interval velocity is then derived as $5.90 \mathrm{~km} / \mathrm{sec}$ for $\mathrm{D}_{1}$ or as $5.86 \mathrm{~km} / \mathrm{sec}$ for $\mathrm{D}_{8}$; the latter is the minimum. If we assume that the low velocity region corresponds to the area of anomalous wave propagation as shown by Hirata and UCHIYAMA (1981), the refracted waves at $D_{1}$ and $D_{3}$ are nearly of equal wave path length in the region for SP. VI. Thus the velocity is estimated to be as low as $5.4 \mathrm{~km} / \mathrm{sec}$ under the Sakurajima Volcano.

The travel time of the first arrival at $\mathrm{E}_{7}$ or $\mathrm{E}_{8}$ gives the delay time at the shot point SP. 0 of $0.33 \mathrm{sec}$ if we assume the velocity in the fifth layer along the N-S profile in the Osumi Peninsula as $5.9 \mathrm{~km} / \mathrm{sec}$, which is the velocity presented in Paper II. It is, however, only a half of the delay time estimated from the structure model in Paper II. Then slight modifications will probably be required for the previous model along the N-S profile in the Osumi Peninsula. Although such a low delay time cannot entirely be ruled out at the shot point because of insufficient data, a reasonable delay time will be obtained if the velocity of the layer increases to as high as $6.0 \mathrm{~km} / \mathrm{sec}$ around the shot point. It is shown in the contour map of Yokoyama and Okawa [see TsuBor (1979, p. 254)] that Bouguer anomalies are rather high around there: $35-40 \mathrm{mgal}$. The region of high Bouguer anomalies may possibly correspond to a high velocity region.

\section{Conclusion}

Analyzing all seismic refraction data in South Kyushu together, we present a model of the upper crust. It is composed of 5 layers: the superficial layer of $V_{\mathrm{P}}=1.0 \mathrm{~km} / \mathrm{sec}$, the second of $V_{\mathrm{P}}=2.7 \mathrm{~km} / \mathrm{sec}$, the third of $V_{\mathrm{P}}=3.9 \mathrm{~km} / \mathrm{sec}$, the fourth of $V_{\mathrm{P}}=4.9 \mathrm{~km} / \mathrm{sec}$ and the fifth. In the fifth layer, lateral variations in wave velocity occur: $V_{\mathrm{P}}=6.1 \mathrm{~km} / \mathrm{sec}$ in the western part of the E-W profile across South Kyushu, $V_{\mathrm{P}}=5.9 \mathrm{~km} / \mathrm{sec}$ in the eastern part and $V_{\mathrm{P}}=5.7 \mathrm{~km} / \mathrm{sec}$ in the central part. The east end of the low velocity region is fixed at the distance of $60 \mathrm{~km}$ from the shot point SP. I along the profile. This is deduced from the geological distributions of the Shimanto group, the sediments of late Mesozoic. Then the width of the region is estimated as $14 \mathrm{~km}$.

In the region of $V_{\mathrm{P}}=6.1 \mathrm{~km} / \mathrm{sec}$, the depth of the fifth layer is about $3 \mathrm{~km}$ in the west and increases to about $4 \mathrm{~km}$ to the east. An abrupt subsidence of 
the layer occurs at the west boundary of the low velocity region. It is gradually recovered to the east. Therefore, the depression indicated in Paper I is confirmed. The layer again subsides by about $2 \mathrm{~km}$ to the west of Miyakonojo City, where a geological boundary between the Shimanto group (Cretaceous) and Nichinan group (Paleogene) exists. These variations in the depth of the fifth layer are readily interpreted using gravity data surveyed by Yokoyama and Okawa [see TsuBor (1979, p. 254)].

The difference in wave velocity of the fifth layer between the E-W profile and the N-S profile in the Osumi Peninsula, which appeared in the previous models (Paper II), is probably spurious because $V_{\mathrm{P}}=5.9 \mathrm{~km} / \mathrm{sec}$ is observed in the E-W profile.

Reduced travel times corrected with delay time reveal the decrease in wave velocity not only under the Sakurajima Volcano but almost all over the highly attenuative region. In particular, an intensive decrease is possible under the Sakurajima Volcano since delays in travel time are most predominant in the wave paths across there. A velocity as low as $5.4 \mathrm{~km} / \mathrm{sec}$ is estimated under the Sakurajima Volcano if the location of the low velocity region is appropriately assumed.

I am grateful to Professor Y. Satô for kindly reading the manuscripts and giving valuable comments. Thanks are due to Professor I. Yokoyama for providing unpublished gravity data for South Kyushu, to Professor S. Asano who gave me important advice and to Mr. K. Ôki for geological information on South Kyushu. Seismograms and seismic record sections were prepared by the Research Group; the members are Drs. K. Ono, K. Ito, I. Hasegawa, K. Ichikawa, S. Iizuka and H. Suzuki. I would like to thank all of them.

\section{Appendix 1. $T^{\prime}$ or $T^{\prime \prime}$ Travel Time}

For the sake of a brief explanation of $T^{\prime}$ or $T^{\prime \prime}$ travel time, we deal with a two-layered half space; $V_{1}$ and $V_{2}$ refer to wave velocities in the overlying layer and the half space, respectively. Let $\mathrm{J}$ and $\mathrm{K}$ be shot points and $\mathrm{P}$ be an observation site (Fig. 12). The $T^{\prime}$ travel time at the P-site for the J-shot is defined by

$$
T_{2 \mathrm{JP}}^{\prime}=T_{2 \mathrm{JP}}-\left(T_{2 \mathrm{JP}}+T_{2 \mathrm{KP}}-T_{2 \mathrm{JK}}\right) / 2,
$$

where $T_{\text {2JP }}$ is the travel time of refracted waves at the P-site for the J-shot. Decriptions of $T_{2 \mathrm{KP}}$ and $T_{2 \mathrm{JK}}$ are similar to that of $T_{2 \mathrm{JP}}$. If irregularities in the surface of the half space are not intensive, or $d h / d \Delta \ll 1$, and if both $T_{2 \mathrm{JP}}$ and $T_{2 \mathrm{JK}}$ belong to the refracted waves from the same region, we can approximate Eq. (A.1) by

$$
T_{2 \mathrm{JP}}^{\prime}=e_{2 \mathrm{~J}}+\Delta_{\mathrm{JP}} / V_{2},
$$

where $e_{2 \mathrm{~J}}$ is the delay time of the half space at the $\mathrm{J}$-shot point and $\Delta_{\mathrm{JP}}$ is the distance from the $\mathrm{J}$-shot to the P-site. Then the inverse of the gradient of the $T^{\prime}$ travel time curve gives the velocity in the half space.

Since the delay time of the half space at the P-site, $e_{2 \mathrm{P}}$, is given by 


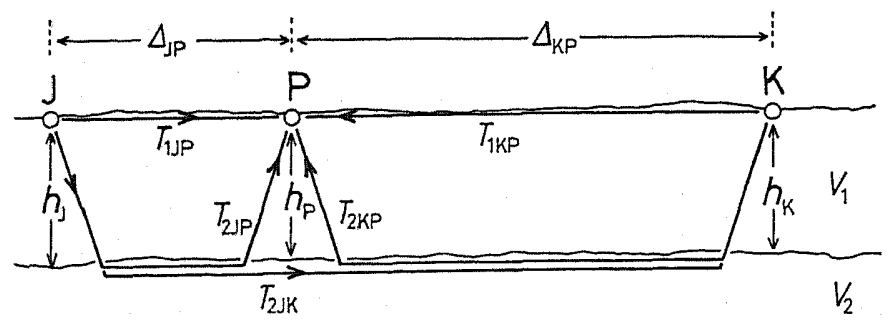

Fig. 12. Wave-paths in a two-layered half space $\left(V_{1}<V_{2}\right)$. The shot points are at $\mathrm{J}$ and $\mathrm{K}$, and an observation is made at $\mathrm{P}$. Travel times are indicated by $T_{1}$ for the direct wave and by $T_{2}$ for the refracted wave.

$$
e_{2 \mathrm{P}}=\left(T_{2 \mathrm{JP}}+T_{2 \mathrm{KP}}-T_{2 \mathrm{JK}}\right) / 2,
$$

then we obtain the depth of the half space, $h_{\mathrm{P}}$ by

$$
h_{\mathrm{P}}=e_{2 \mathrm{P}} V_{1} /\left[1-\left(V_{1} / V_{2}\right)^{2}\right]^{1 / 2} \text {. }
$$

The $T^{\prime \prime}$ travel time is given by an equation very similar to (A.1), or

$$
T_{2 \mathrm{JP}}^{\prime \prime}=T_{1 \mathrm{JP}}-\left(T_{1 \mathrm{JP}}+T_{2 \mathrm{KP}}-T_{2 \mathrm{JK}}\right) / 2,
$$

where $T_{1 \mathrm{IP}}$ is the travel time of direct waves at the P-site for the J-shot. Namely, the $T^{\prime \prime}$ travel time is derived from a combination of waves from different refractors: a refractor and its overlying layer. Under the condition of $d h / d \Delta \ll 1$, we have an approximated equation

$$
T_{2 \mathrm{JP}}^{\prime \prime}=\left(e_{2 \mathrm{~J}}-e_{2 \mathrm{P}}\right) / 2+\Delta_{\mathrm{JP}} / V_{1,2},
$$

where

$$
V_{1,2}=\left(1 / V_{1}+1 / V_{2}\right) / 2 \text {. }
$$

Then the apparent velocity $V_{1,2}$ is obtained from the inverse of the gradient of th $T^{\prime \prime}$ travel time curve. In this example, as easily seen from (A. 6), the intercept time of the $T^{\prime \prime}$ travel time curve is nearly zero. This is a special case when an overlying layer is superficial.

For an $n$-layered half space, almost the same descriptions will be given. More detailed explanations are contained in Tazime's book (TAZIME, 1977, pp. 66-97).

Appendix 2. Seismic Record Sections on the S- and T-Profiles

Seismic record sections for refraction observations of SP. I and SP. II blasted in 1973 are shown in Fig. 13. Although first arrivals for SP. II are obscured (Fig. 13(b)), difficulties in picking them up are diminished by careful examination of seismograms on the record section.

Figure 14 shows record sections for SP. III, SP. IV and SP. V of 1974. First arrivals are clearly recognized at every site. 


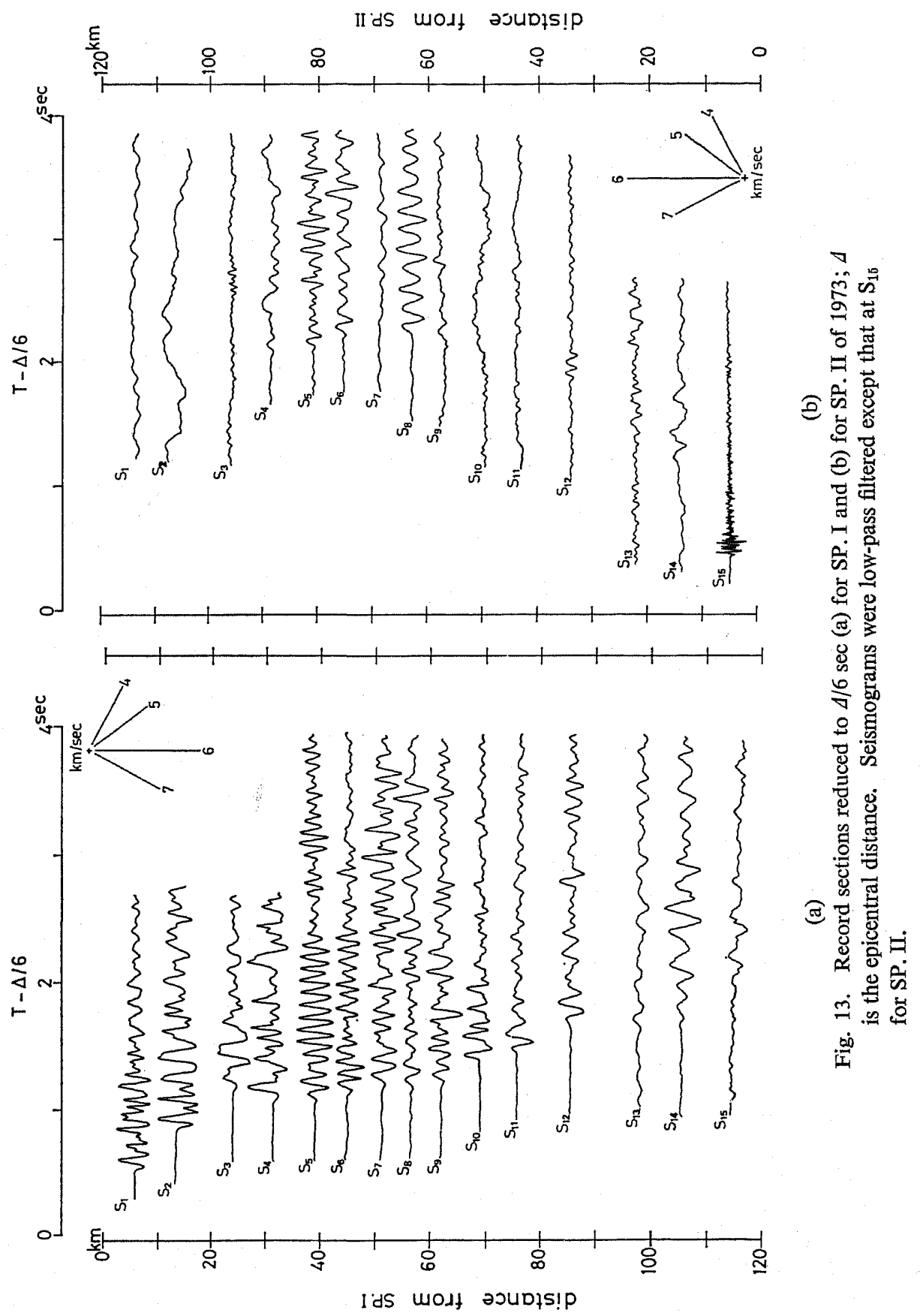




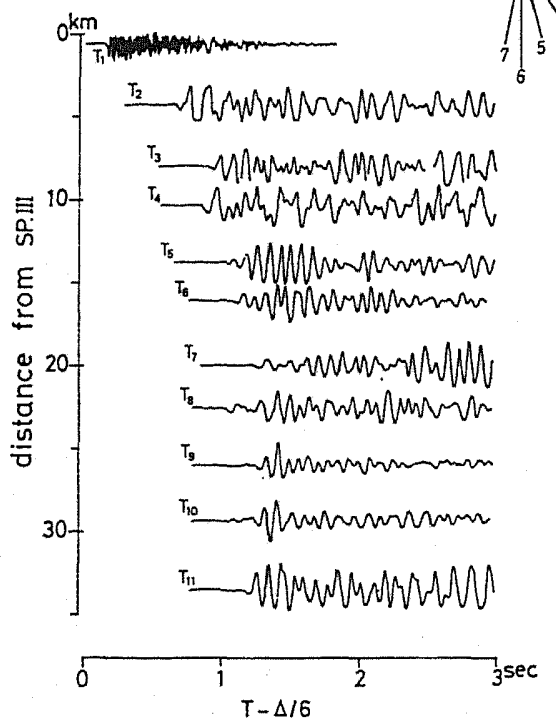

(a)

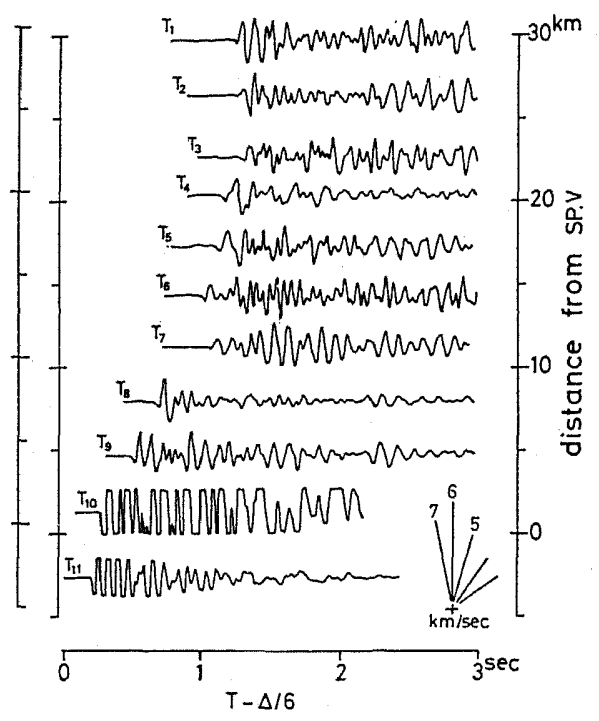

(b)

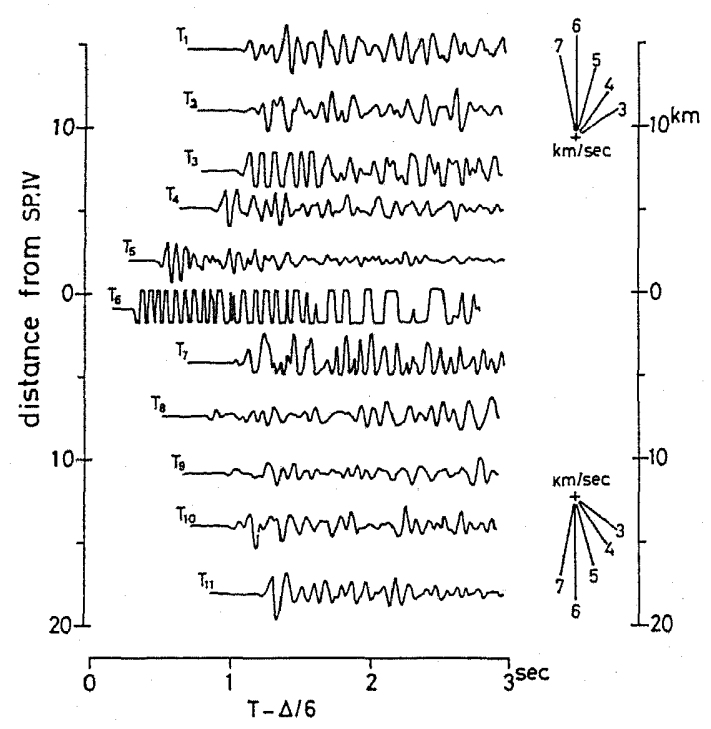

(c)

Fig. 14. Record sections reduced to $4 / 6 \mathrm{sec}$ (a) for SP. III, (b) for SP. V and (c) for SP. IV of 1974. Seismograms were low-pass filtered except that at $T_{1}$ for SP. III. 


\section{REFERENCES}

HaGiWARA, T., New method for the analysis of time-distance curves in the case of non-uniformly inclined bed rock surface, Zisin (J. Seismol. Soc. Japan), 10, 463-468, 1938 (in Japanese).

Hashimoto, I., I. Hayami, and N. Noda, The Palaeozoic and Mesozoic strata in the Gumizaki District, Kagoshima Prefecture, Rep. Earth. Sci., Dept. General Educ., Kyushu Univ., 17, 4350, 1972 (in Japanese).

Hirata, T. and T. UChryama, Damping area in the Aira Caldera of South Kyushu, Zisin ( $J$. Seismol. Soc. Japan), Ser. 2, 34, 435-437, 1981 (in Japanese).

Imat, I., Y. Teraoka, K. Ono, K. MAtsui, and K. OKumura, 1: 500,000 geological map, sheet 15, Kagoshima, Geol. Surv. Japan, 1980.

OkadA, H., S. SuzuKI, and S. Asano, Anomalous underground structure in the Matsushiro Swarm Area as derived from a fan shooting technique, Bull. Earthq. Res. Inst., 48, 811-823, 1970.

Omote, S., T. Mitsunami, Y. Iwao, M. Hanai, and B. Takeuchi, Dynamic properties of "Shirasu" layer as deduced from the S wave observations, Butsuri-tanko (Geophys. Explor.), 28, 23-29, 1975 (in Japanese).

ONo, K., K. ITo, I. HASEGAWA, K. IChIKAWA, S. ItzuKa, T. KaKuTA, and H. SuzuKi, Explosion seismic studies in South Kyushu especially around the Sakurajima Volcano, J. Phys. Earth, 26 Suppl., 309-319, 1978.

Ono, K., K. Ito, S. Irzuka, I. Hasegawa, T. Hiroshima, T. Kakuta, K. Ichikawa, and H. SUzUKI, Explosion seismic studies near and around Sakurajima Volcano, in Volcanism of Island Arcs, ed. A. Fedotov and P. I. Tokarev, pp. 43-54, Nauka, Moskow, 1977 (in Russian).

TALWANI, M., J. L. WoRzel and M. LANDISMAN, Rapid gravity computations for two-dimensional bodies with application to the Mendocino submarine fracture zone, $J$. Geophys. Res., 64, 49-59, 1959.

TAZIME, K., Refraction shooting on the experimental field for small explosions in the neighbourhood of the City of Mitsuke, Niigata Prefecture, Geophys. Bull. Hokkaido Univ., 11, 113168, 1963 (in Japanese).

TAzIME, K., Seismic prospecting for civil engineering, Maki Shoten, Tokyo, 1977 (in Japanese). Tsubor, C., Gravity field on the Earth, 2nd, ed. Iwanami Shoten, Tokyo, 1979 (in Japanese). 